Article

\title{
Strategies of Pre-Service Early Childhood Teachers for Solving Multi-Digit Division Problems
}

\author{
Zaira Ortiz-Laso *(i) and José-Manuel Diego-Mantecón *(1) \\ Department of Mathematics, Statistics and Computer Science, Faculty of Science, University of Cantabria, \\ 39005 Santander, Cantabria, Spain \\ * Correspondence: zaira.ortiz@unican.es (Z.O.-L.); josemanuel.diego@unican.es (J.-M.D.-M.); \\ Tel.: +34-625-443-698 (Z.O.-L.); +34-655-457-107 (J.-M.D.-M.)
}

Received: 16 October 2020; Accepted: 3 December 2020; Published: 7 December 2020

\begin{abstract}
Unlike previous research, this study analyzes the strategies of pre-service early childhood teachers when solving multi-digit division problems and the errors they make. The sample included 104 subjects from a university in Spain. The data analysis was framed under a mixed-method approach, integrating both quantitative and qualitative analyses. The results revealed that the traditional division algorithm was widely used in problems involving integers, but not so frequently applied to problems with decimal numbers. Often, number-based and algebraic strategies were employed as an alternative to the traditional algorithm, as the pre-service teachers did not remember how to compute it. In general, number-based strategies reached more correct solutions than the traditional algorithm, while the algebraic strategies did not usually reach any solution. Incorrect identifications of the mathematical model were normally related to an exchange of the dividend and divisor roles. Most pre-service teachers not only failed to compute the division, but also to interpret the obtained solution in the problem context. The study concludes that, during their schooling, students accessing the Degree in Early Childhood education have not acquired the necessary knowledge and skills to solve multi-digit division problems, and thus the entrance requirements at the university must be rethought.
\end{abstract}

Keywords: multi-digit division; division; strategy; pre-service teachers; early childhood education

\section{Introduction}

Education has experienced a worldwide reform in recent decades. Curricula and official documents recognize problem-solving as a key component in mastering mathematics. The use of reasoning and problem-solving strategies to obtain contextual solutions has been promoted across countries [1,2]. These demands are transversal to compulsory educational systems from primary to secondary education. Although arithmetic operations, in general, have been extensively investigated [3], division has received less attention than addition, subtraction, or multiplication [4-7]. Most studies of division have focused on examining informal strategies with few studies devoted to assessing strategies on multi-digit division problems [3]. Multi-digit division problems go beyond simple multiplication facts and involve high numbers or decimals numbers in a problem-solving context [8]. These problems are useful for analyzing strategy choice as the "complexity of the problems allows for the use of a wider range of strategies" [8] (p. 52).

Most research on this topic has been undertaken with primary school students $[3,5,6,8-13]$ and conducted by Hickendorff and Fagginger-Auer and their colleagues in the Netherlands [3,5,6,8-10]. In that country, the Realistic Mathematics Education (RME) reform has heavily influenced school teaching by promoting the learning of flexible strategies and introducing the traditional division algorithm in the last year of primary school [6]. Other countries worldwide, like Spain, are characterized 
by a more algorithm-oriented instruction that introduces the division algorithm in the early years of primary education [14]. As stated above, the study of multi-digit division strategies in a problem-solving context has usually been undertaken with primary school students. As far as we know, investigations with secondary school students or pre-service teachers are rarely carried out. We only found the ones of $[15,16]$ with secondary school students in Chile and pre-service primary teachers in Spain, respectively. Other studies on multi-digit division strategies were conducted, but not in a problem-solving context (e.g., $[17,18])$. Strategies of pre-service early childhood teachers have not been assessed. This may be because, as stated by [19], the training of such teachers is a more recent research field.

In early childhood education, children commonly undertake sharing-out actions over items and collections. Thus, early childhood teachers must have the necessary subject matter and pedagogical knowledge [20-22] to develop children's skills in division problems. As suggested by [19], educators in preschool education require deep knowledge of arithmetic operations. They should, for example, be able to conceptualize division, represent it in a variety of ways, and know its curricular directions [23]. They should also distinguish the different types of division problems (e.g., quotitive and partitive), switching efficiently from one strategy to another, as well as interpreting the division remainder. Regarding solution strategies, teachers must be able to execute "direct and nondirect modeling with counting", and to compute "additive or subtractive strategies" using "derived facts" [24]. The first strategy implies, for instance, counting using pictorial or concrete representations. The second strategy involves knowing additive and multiplication facts to make operations. This latter approach often entails solving divisions considering the place value of the numbers, and also handling formal strategies like the sequential ones.

As a consequence of the above, the current study aims to examine pre-service early childhood teachers' strategies for solving multi-digit division problems. We attempt to assess whether teachers have acquired the problem-solving knowledge and skills promoted by official curricula across educational systems and thus whether recent reforms are impacting on our students' division strategies. We also seek to investigate whether or not future early childhood teachers make use of arithmetical strategies, as primary school students do [3,5,6,8-13], or by contrast, they additionally incorporate algebraic strategies as observed with secondary school students [15]. In a general problem-solving context with pre-service primary teachers, research suggests these teachers alternatively apply arithmetical and algebraic strategies, depending on problem characteristics $[25,26]$.

\section{Division Problems}

Operating divisions entails complex processes; it requires, for instance, mastering multiplication and high skills to undertake quick calculations $[17,18]$. Two division models are normally distinguished: quotitive and partitive. The quotitive model, also called measurement division, demands calculating the number of subsets when the subset size is known [27], and the divisor is an intensive quantity expressing the cardinal of items per subset $[28,29]$. The following is an example of a quotitive problem: One hundred and fifty marbles are shared equally among the children. If they each have five marbles, how many children are there? The partitive division model, also called sharing division, entails calculating the size of the subset when knowing the subset number [27]. The divisor is equal to the number of subsets needed [29,30] and the quotient is an intensive quantity [28]. An example of a partitive division problem is: One hundred and fifty marbles will be shared equally among five children. How many marbles will each child receive? Researchers across international contexts have studied the difficulty of solving quotitive and partitive division problems. For instance, [29] revealed that English primary students find integer quotitive problems significantly easier to solve than partitive ones. By contrast, [31] discovered that Italians achieve better results on whole-number partitive problems than on quotitive ones; [32] concluded similar results to those of [31] with a sample of American pre-service primary teachers.

Most incorrect solutions of partitive problems occur when the divisor is an integer number greater than the dividend; in this case, subjects tend to invert the role of these numbers. When the dividend 
is a decimal number smaller than an integer divisor, students attain a correct expression easier than when problems comprise integer numbers only. This is because solvers try to avoid having a decimal divisor [31,32]: "the faulty rule that the divisor should be a whole number seems to have a greater strength than the faulty rule about the relative sizes of divisor and dividend" [32] (p. 100).

When studying division problems, researchers place emphasis not only on the dividend and divisor components, but also on the remainder. A division-with-remainder (DWR) problem results in a noninteger division outcome that needs to be interpreted in the real-world setting [33,34]; [34] found that Chinese pre-service primary teachers provided highly realistic answers when solving DWR problems. Similar results were provided by [16] in a study with Spanish pre-service primary teachers. The outcomes obtained by [16] and [34] are contrary to those obtained by [6,33,35-37] with Spanish pre-service primary teachers, Spanish secondary school students, and Dutch, Chinese, American, and Flemish primary school students. In the five aforementioned studies, the individuals usually performed a correct computation of the division; however, they were unable to give appropriate results, as they failed to interpret the remainder in the context of the problems. When solving DWR problems, some solvers do not seem to have an awareness of the situational context; others show some apparent awareness of it, although they are still unable to provide a contextual solution [38]. According to [36], the remainder size is not related to attempt a contextual interpretation of the solution.

\section{Strategies for Solving Division Problems}

The selection of strategies is a key point in problem-solving [12]. Strategy use implies four actions: "what strategy to use", "when to use it", "how to execute it", and "how to choose it" [39]. Handling these actions enhance solvers' speed and accuracy when searching for a solution, as they will tend to employ the fastest and most accurate strategy in their repertoire [40]; that is, they will select and apply what is called an adaptive strategy $[3,40,41]$.

In single-digit division problems, authors often distinguish between retrieval and computational strategies [40]. The former implies "knowing the answer and retrieving it directly from memory" [7] (p. 230), while the latter requires making calculations through a computation process [41]. In multi-digit division problems, the retrieval strategy is not feasible, and a computational strategy through mental or written processes is required [41]. There are two types of computational strategies for solving multi-digit division problems, called digit-based and number-based $[6,10,41]$. Number-based strategies respect the place value of digits, while digit-based strategies ignore the place value [8]. Distinguished by [41], direct division and indirect multiplication are two ways to solve multi-digit divisions. Both types can be executed through at least four number-based strategies: sequential, decomposition, varying, and column-based.

Sequential strategies are based on additive reasoning and involve forward or backward movements on the mental line [41]; repeated addition, repeated subtraction, and adding/subtracting multiples are examples of sequential strategies. In repeated addition, the divisor is added until the dividend is achieved [7], while in repeated subtraction the divisor is subtracted from the dividend until zero is reached [12]. These two strategies can also be used by adding/subtracting multiples of the divisor. Repeated addition and subtraction are considered rudimentary strategies that can be used even by students with no instruction in division [30]. Some authors consider these strategies part of the low-level of chunking category [3,42], while others refer to them as individual strategies [12,43].

In the decomposition strategy, called "splitting and adding" or "partitioning" by [11,42], respectively, the dividend is decimally split [41]. In direct divisions, the dividend is split into smaller numbers and partial results are added; for example, the division $266 \div 14=19$ is computed as follows: $140 \div 14=10,70 \div 14=5,56 \div 14=4$ so, $10+5+4=19$. In indirect multiplications, separate multiplications of the divisor are added until reaching the dividend: $15 \times 14=210,4 \times 14=56$ so, $15+4=19$.

Varying strategies, also called simplifying or shortcut, usually involve adapting numbers to facilitate operations [5,41]. Three types of varying strategies are highlighted: compensation, 
decomposing or changing multiplicatively, and $10 \times \mathrm{N}$ patterns. Compensation implies changing the dividend to a higher number (multiple of divisor) and then subtracting partial results $[11,12,43]$. Applying this strategy, the division $266 \div 14$ could be executed by taking 280 as the dividend to solve a more convenient division $(280 \div 14=20)$, and then compensating the partial result by subtracting $20-1=19$. One is the result obtained from $(280-266) \div 14$. "Decomposing or changing multiplicatively" entails factorizing the divisor or canceling the common factor in both dividend and divisor, without involving $10 \times \mathrm{N}$ patterns [12]. An example of divisor factorizing is $266 \div 14=266 \div 7 \div 2$, while $266 \div 14=(133 \times 2) \div(7 \times 2)=133 \div 7$ is an example of canceling the common factor. Finally, the "10 $\times$ N patterns" varying strategy involves dividing by multiples of $10[11,12]$. We can divide the dividend by 10 and subsequently multiply the interim result by 10 $(2660 \div 14 ; 266 \div 14=19 ; 2660 \div 14=19 \times 10=190)$, or divide the dividend and divisor by 10 .

The column-based strategy, also labeled chunking strategy with schematic notation [42], is a vertical schematized version of the repeated subtraction [41]. Although this strategy operates on whole numbers, it may be interpreted as a standard algorithm because of its step-by-step procedure with vertical notation $[6,10]$.

Digit-based strategies, unlike number-based ones, operate on single digits in a procedural way usually from left to right [41]. These strategies comprise the traditional algorithm, where the subtractions of a multiple of the divisor must be optimal [3]. Notation for this strategy varies cross-culturally; the Spanish notation, for instance, is similar to the French, but differs from the Israeli, Dutch, and American forms (Figure 1).

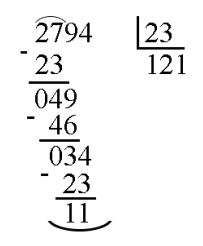

Spain

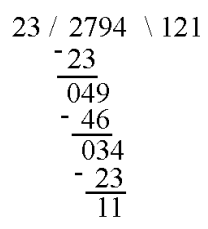

The Netherlands

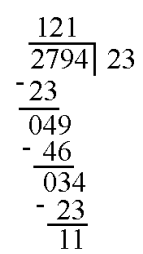

Israel

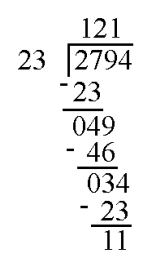

The United States

Figure 1. Notation of the Spanish, Dutch, Israeli, and American traditional algorithm.

In addition to the above, other strategies have been identified, such as "guess and check" [8]. In the "guess and check" strategy, the value is predicted and then verified to see whether (or not) it fits the problem conditions [44]. Students with instruction in algebra (e.g., secondary students and pre-service teachers) attempt to employ an algebraic solution, even when the application of arithmetic operations is more straightforward $[15,25,26]$. Algebraic solutions are defined as those containing at least one equation in which known and unknown values are operated to attain the final outcome $[25,26]$.

\section{Strategy Choice and Errors When Solving Multi-Digit Division Problems}

Some studies have shown that students no instructed in division employ diverse strategies, including "direct modeling with counting", "no direct modeling, with counting, additive, or subtractive strategies", and "use of known or derived facts" [24,45]. Instructed students, however, tend to apply more structured procedures, identifying a progression from mental and informal strategies to written approaches $[3,13,14,16,36]$. There is evidence that a student's high performance on multi-digit division problems is positively associated with written strategies $[3,8,9]$. Strategy selection for this type of problem may depend on various factors including the characteristics of the numbers involved in the problem $[3,12]$, the approach used to tackle the problem $[3,8]$, and the instructional setting of the solver $[6,10,14,46]$. Concerning number characteristics, in problems where dividend and divisor have a common factor, as well as in problems where the dividend or divisor is a multiple of ten, varying strategies are often the most suitable. These strategies are, however, rarely used by students [5].

Strategy selection depends on the approach used to solve the problem and whether this is mental or written. Algorithmic strategies, including both digit-based (i.e., the traditional algorithm) and 
column-based ones, are frequently employed under a written approach, while decomposition and varying strategies are common in mental processes [8]. The strategy choice also varies in relation to the instructional setting in which students are located. The traditional algorithm is usually the most recurring strategy in instructional contexts like those of Spain, England, Belgium, Turkey, and the United States $[6,14,16,19,36,47]$, while in settings influenced by Realistic Mathematics Education (RME), as in the Netherlands, students tend to use the column-based strategy [3,8]. It is noteworthy that once the traditional algorithm is taught, its use often increases through the educational system, with students shifting from their repertoire of informal strategies to digit-based strategies [14]. In a study with 12- to 14-year-old Chilean students, [15] suggested that it may also occur when algebra is taught. They reported the application of the proportion formula (also called rule of three) to solve a division problem.

Strategy choice influences solvers' success. [36] found that American students had more difficulty in performing division correctly when applying the traditional algorithm rather than sequential strategies. This result concurs with a study of Spanish pre-service teachers [16]. As stated by [14], the "inverse algorithm" error emerges in Spanish primary school students when they are introduced to the traditional algorithm. The inverse algorithm error occurs when students apply the inverse operation to solve a problem; in this case, multiplication rather than division. Other errors identified when employing the traditional algorithm are related to the use of zero and the remainder [13]. Although the traditional algorithm is generally reported as the least successful strategy, [42] found still worse results when fourth-grade Dutch students applied decomposition strategies. For [42], the most effective strategies in their sample were column-based. Years later, another study with Dutch primary school students [5] suggested that varying strategies are also the most successful ones.

These discrepancies may be due to the fact that strategy use is consistent with the teaching practice $[6,10,13]$ and textbooks usage $[3,10]$. In particular, students' choice of traditional algorithm and column-based strategies is related to the instruction they receive $[6,8]$. To learn more about the success of the strategy used, it is important to analyze in-depth the contexts in which strategies are selected and applied.

\section{Objectives and Methodology}

As shown above, a wide range of studies has identified and evaluated the strategies employed by primary school students on multi-digit division problems [3,5,6,8-13,47]. Investigations with secondary school students and pre-service primary teachers, however, have been rarely conducted, while the strategies employed by future early childhood teachers on multi-digit division problems have remained unexplored. We thus need to carry out investigations with pre-service early childhood teachers to analyze whether or not they have acquired the division strategies promoted by official curricula. In this study, we will examine whether these pre-service teachers employ the adaptive strategies they should have learned across their school instruction. Potential results from the present research may contribute to understanding future teachers' choice of adaptive division strategies in a problem-solving context, and identifying their knowledge and skills on this arithmetic operation.

\subsection{Sample Selection and Description}

The sample comprised 104 pre-service early childhood teachers from a university in North Spain. When participating in the study, they were in the second year of the Early Childhood Education Degree, close to taking the only mathematics course taught in this degree. This course belongs to the second semester of the second year, and covers mainly pedagogical content knowledge on the blocks of Mathematical Logic, Numbers, Geometry, and Quantity, representing 7.5 units in the European Credit Transfer System (ECTS). Concerning the topic of divisions, the course includes a brief instruction to partitive and quotitive models, and describes informal solution strategies noted in [24,45]. However, this course does not assess students' skills in problem-solving, nor in their previous skills on arithmetic operations. 
Participants ranged in age from 19 to 44, with the majority aged 19-23. In the pre-university stage, most participants earned undergraduate degrees in the Humanities and Social Sciences; approximately one-third entered university after taking an advanced vocational course of two years. These pre-service teachers are the result of the two last Spanish educational laws: Organic Law of Education (LOE, Ley Orgánica de Educación) and Organic Law for Improving the Quality of Education (LOMCE, Ley Orgánica para la mejora de la calidad educativa). According to these laws, students should be able to work out operations through written and mental processes using their own strategies. This implies the ability to use all number-based strategies mentioned above, except the column-based one. The assessment standards include students' ability to compose and decompose multi-digit numbers, as well as their ability to apply number and operation properties. In addition to number-based strategies, students should have automated the traditional division algorithm [1,2].

\subsection{Research Strategy and Methods}

To accomplish the study objectives, a mixed-method approach was adopted. Though mainly quantitative, a qualitative approach was also undertaken [48]. The qualitative approach helped identify and understand the reasons behind each strategy selection, and the factors influencing incorrect applications. The quantitative approach facilitated the categorization of strategies and the comparison of errors.

A questionnaire and cognitive interviews were employed as data collection methods. The questionnaire contained two parts: one for gathering personal data and the other for collecting responses to the posed problems. Three division problems were interspersed with three nondivision problems "to reduce the likelihood that correct answers would result from guessing" [32] (p. 96). This strategy was employed previously in studies of this topic [31,32]. The three division problems were multi-digit, involving integer numbers with various digits, or decimal numbers. The problems were contextualized in a monetary setting, familiar to anyone. The cognitive interviews collected in-depth data for understanding the cognitive processes involved to attain the solution [49]. Participants were informed of the objective of the study and all agreed to participate. The questionnaires were administered at the beginning of the second semester. While completing the questionnaire, participants were encouraged to write down their entire solution process, including arithmetic operations, drawings, and verifying solutions. The only restriction was that calculators were not allowed.

\subsection{The Problems}

The problems were presented to participants in their mother tongue. For this article, they were translated from Spanish into English following the recommendations of [50] (Table 1).

Table 1. The three proposed multi-digit division problems.

\begin{tabular}{cc}
$\begin{array}{c}\text { Problem Number } \\
\text { (Short Name) }\end{array}$ & Posed Problem \\
\hline $\begin{array}{c}\text { Problem } 1 \\
\text { (inheritance) }\end{array}$ & $\begin{array}{c}\text { A grandfather wants to distribute his inheritance of } € 3010 \text { equally among his } \\
\text { three grandchildren. How much money will each heir receive? }\end{array}$ \\
\hline $\begin{array}{c}\text { Problem } 2 \\
\text { (a meal) }\end{array}$ & After paying for a meal, eight friends are sharing the change of $€$ 7.2. How much \\
does each one receive?
\end{tabular}

Problem 1 (inheritance) involves a two-integer division with a nondivisible remainder [37], resulting in a decimal quotient. The dividend (3010) is a four-digit number and the divisor (3) a single-digit, representing a partitive model where the dividend is greater than the divisor. Concerning the context, it is not feasible to fairly split $€ 3010$ among three people because the result is a recurring decimal. Problem 2 (a meal) is a one-step division problem containing decimal numbers. It represents 
a partitive model where the dividend is a decimal number (7.2), the divisor an integer (8), and the remainder is zero. This problem violates the partitive division rule because the dividend is lower than the divisor [31]. Problem 3 (chewing gum) is a one-step division problem in which both the dividend (4.5) and divisor (0.9) are decimal numbers. It involves a quotitive or measurement division, where the dividend is higher than the divisor.

\subsection{Data Analysis}

The pre-service teachers' responses to the three problems were examined and coded as "correct", "incorrect", and "left blank". Given the characteristics of the inheritance problem, their responses were also tagged as "partially correct". Responses were labeled as correct when models were accurately provided, and operations perfectly executed. The absence of measurement units (euros per person and packages of chewing gums) in the solution was not considered an error. In the inheritance problem, solutions were coded as correct when reporting the decimal number ( $€$ 1003.33) or the integer number ( $€ 1003)$, in addition to any of the following three statements: 1 cent is left over, $€ 1$ is left over, or the remainder cannot be split into three parts. Correct quantitative solutions without any interpretation of the remainder were tagged as partially correct, while erroneous solutions were coded as incorrect. Solutions were coded as left blank when participants did not provide a respond or simply transcribed the problem data without any attempt to use it.

The cognitive interviews allowed us to classify the solution strategies and errors. The strategies were labeled "sequential", "decomposition", "varying", "column-based", "traditional algorithm", "guess and check", and "algebraic", as defined in Section 3.

\section{Results}

\subsection{Inheritance Problem}

All pre-service teachers attempted to solve the inheritance problem: $93.3 \%$ built an appropriate mathematical model, $8.7 \%$ achieved a correct solution, and $26.0 \%$ a partially correct solution. As shown in Table 2, three solution strategies were identified: "traditional algorithm" (Section 6.1.1), "decomposition" (Section 6.1.2), and "algebraic" (Section 6.1.3).

Table 2. Percentage of employed strategies and correct solutions, approaches, and processes on the Inheritance problem.

\begin{tabular}{cccccc}
\hline Strategy Name & $\begin{array}{c}\text { Strategy } \\
\text { Employed }\end{array}$ & $\begin{array}{c}\text { Correct } \\
\text { Solution }\end{array}$ & $\begin{array}{c}\text { Partially Correct } \\
\text { Solution }\end{array}$ & $\begin{array}{c}\text { Correct } \\
\text { Approach }\end{array}$ & $\begin{array}{c}\text { Correct } \\
\text { Process }\end{array}$ \\
\hline Traditional & $74.0 \%$ & $11.7 \%$ & $26.0 \%$ & $100 \%$ & $42.9 \%$ \\
algorithm & $19.2 \%$ & $0 \%$ & $35.0 \%$ & $100 \%$ & $100 \%$ \\
Decomposition & $6.7 \%$ & $0 \%$ & $0 \%$ & $0 \%$ & $0 \%$ \\
Algebraic & & & & & \\
\hline
\end{tabular}

\subsubsection{Traditional Algorithm}

All participants understood the word problem and transformed it into an appropriate mathematical model; however, only $11.7 \%$ of them attained a correct solution. As Table 2 shows, the traditional algorithm was the most used strategy with $42.9 \%$ of correct computations. For the incorrect computations, two main errors were identified. The first one consisted in omitting zeros from the quotient. The subjects did not append zeros to the quotient when the number corresponding to an interim result, obtained from subtracting a multiple of the divisor and adding a digit from the dividend, was smaller than the divisor. As shown in Figure 2a, the most common solution was $€$ $103 . \hat{3}$ rather than $€ 1003 . \hat{3}$. The cognitive interviews revealed these future teachers did not remember every step of the division algorithm. Subject 60 (woman, aged 24) stated, for example, "Oh! It's true; I have to put another zero in the quotient. ( . . ) To be honest, I can' $t$ remember the whole process 
very well." The second error related to an incorrect remainder as participants considered the division to be finished. As Figure $2 \mathrm{~b}$ exemplifies, the woman (subject 100, aged 24) erroneously stopped the division, adding a mark on the remainder, when she had to continue the process. In this case, subject 100 should have continued dividing the remainder (10) to obtain the last quotient digit: in this case, 3. Result consistency was not established either because, in having do so, she would have realized that 10 cannot be the remainder as it is a larger number than the divisor.

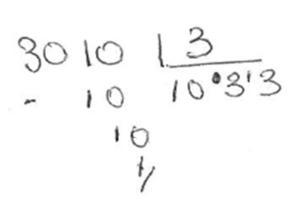

(a)

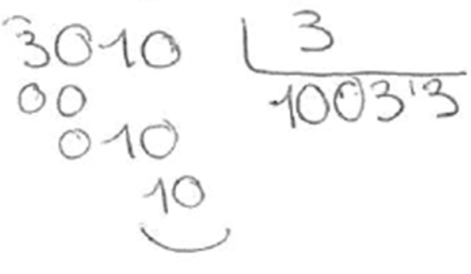

(b)

Figure 2. (a) Omitting a zero in the quotient (subject 60, woman, aged 24) and (b) incomplete division process (subject 100, woman, aged 24).

Two main patterns of responses were identified in the subjects who correctly computed the traditional algorithm, but did not achieve a correct solution: (1) they did not attempt a contextual answer to the problem, or (2) they gave a contextual solution but without providing information about the remainder (what we called a partially correct solution).

About five per cent of the subjects computed the algorithm correctly, but they did not provide a clear contextual response to the problem. Subject 63 (woman, aged 19) claimed, after computing the algorithm, that each heir will receive $€ 1003.3$ (Figure 3). This means that the mathematical solution was not interpreted in the context of the problem, as this response suggests that each heir should receive an infinitely repeating decimal amount of money. The cognitive interviews demonstrated that the pre-service teachers did not have an apparent consideration of the problem contextualization. Subject 94 (woman, aged 21) stated "Yes, that is true. I didn't realize that you can't give anyone a recurring amount of money. I don't know why I answered that way."

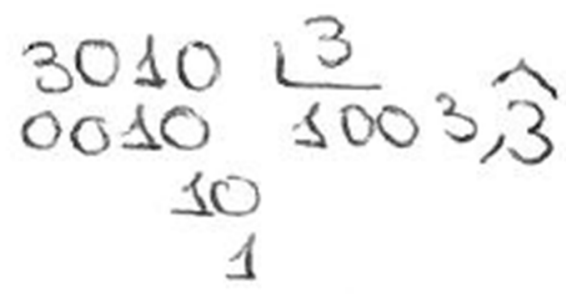

Figure 3. Correct computation of the traditional algorithm with a noncontextual solution (subject 63, woman, aged 19).

About a quarter of the pre-service teachers properly computed the algorithm and partially interpreted the mathematical solution in relation to the context of the problem. Two types of responses were identified in this way: one using only integer numbers, the other using decimal numbers. In the first case, the participants gave the solution by operating integers, as shown in Figure 4 a (subject 4 , woman, aged 23). According to the interviews, these teachers were conscious that when managing euros, you can use two decimal digits, but they lacked confidence to calculate this decimal part. Subject 4, for example, expressed: "I didn't calculate the decimal part, because I was never good at operating with decimal numbers." In contrast to those above, other subjects operated with decimals, arriving at a recurring number in the quotient (Figure $4 b$, subject 72, woman, aged 19), and rounding it off to the nearest hundredths (i.e., $€$ 1003.33). In both cases, with and without the use of decimals, the pre-service 
teachers made a partial interpretation of the mathematical solution. They suggested that the heirs would receive either $€ 1003$ or $€ 1003.33$, but they did not interpret the leftover amount $(€ 1$ or $1 \mathrm{c}$, respectively), leaving the reader to infer by him/herself the precise solution in the context of the problem. The cognitive interviews revealed that most subjects did not make any judgment involving the remainder, despite tackling a familiar financial context. The majority declared that, when solving one-step problems, they focus more on the arithmetic operations than on the outcome interpretation.

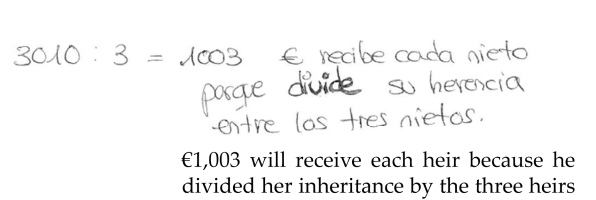

(a)

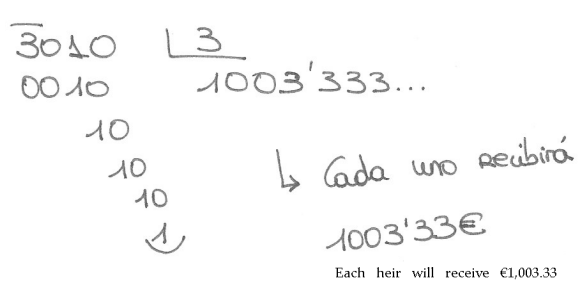

(b)

Figure 4. (a) Dividing integers-partial interpretation of the solution (subject 4, woman, aged 23) and

(b) dividing with decimals-partial interpretation of the solution (subject 72, woman, aged 19).

\subsubsection{Decomposition}

"Decomposition" was the second most commonly employed strategy (19.2\%). Most of the subjects who used this strategy did not provide a contextual solution, though they presented a correct mathematical model and attained a precise mental computation. All subjects employing the decomposition strategy applied it through a mental process: $3000 \div 3=1000$ and $10 \div 3=3 . \hat{3}$. As with the traditional algorithm strategy, many pre-service teachers $(65.0 \%)$ reported an infinite decimal number as the solution, while others indicated a finite decimal number. The ones reporting a finite number did not give a contextual solution; nobody explained that it is not possible to equally divide $€ 3010$ or that $1 \mathrm{c}$ would always be left over. Subject 48 (man, aged 25) correctly expressed the mathematical model $(3010 \div 3)$ and the mental computation $1003.3333 \ldots$ (Figure 5). However, he suggested that the three heirs would obtain an amount of money with infinite decimals, when this is unfeasible in the problem context. Subject 48 did not consider the remainder, not even after being asked to explain his solution process. He simply confirmed the written information.

$3010: 3=1003.3333 \ldots$

\section{El resultado quedaña con infinidad de decimales puesto gue al dividir entre 3 los 10 e no obtenemos una cifra definida.}

The result will have an infinite number of decimals as when dividing $€ 10$ by 3, we don't obtain a definite number

Figure 5. Use of the decomposition strategy with a noncontextual response (subject 48, man, aged 25).

\subsubsection{Algebraic}

An algebraic strategy was attempted by $6.7 \%$ of the pre-service teachers. In particular, they selected the proportion formula (also known as rule of three). The majority of the subjects declared this was the strategy required to solve the problem, but without actually applying it. None of the subjects who actually applied this strategy achieved the correct solution. They showed difficulties in selecting the quantities involved in the algorithm because the problem only gave two quantities, and they did know how to infer the third one. This quantity was "one" because the problem asked for the amount of money that a single heir should receive. After approaching the mathematical model, the pre-service teachers should have applied the arithmetic of fractions to work out the unknown value. However, none of these subjects reached this stage. Subject 99 (woman, aged 20), for example, provided the 
mathematical model in Figure 6, considering $€ 3010$ as the total amount $(100 \%)$, but erred in setting up the ratios of the proportion formula.

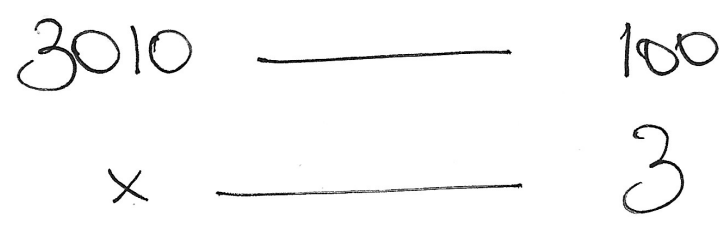

Figure 6. Applying an algebraic strategy with an incorrect mathematical model (subject 99, woman, aged 20).

\subsection{Meal Problem}

In this problem, 59.6\% of the pre-service teachers established an appropriate mathematical model, $36.5 \%$ of the total solved it correctly, and about one fifth left it blank. As shown in Table 3, four solution strategies were identified: "traditional algorithm" (Section 6.2.1), "varying" (Section 6.2.2), "guess and check" (Section 6.2.3), and "algebraic" (Section 6.2.4).

Table 3. Percentage of employed strategies and correct solutions, approaches, and processes on the Meal problem.

\begin{tabular}{ccccc}
\hline Strategy Name & Strategy Employed & Correct Solution & Correct Approach & Correct Process \\
\hline Traditional algorithm & $63.5 \%$ & $39.4 \%$ & $75.8 \%$ & $57.6 \%$ \\
Varying & $7.7 \%$ & $75.0 \%$ & $75.0 \%$ & $75.0 \%$ \\
Guess and check & $5.7 \%$ & $100 \%$ & $100 \%$ & $100 \%$ \\
Algebraic & $3.8 \%$ & $0 \%$ & $0 \%$ & $0 \%$ \\
\hline
\end{tabular}

\subsubsection{Traditional Algorithm}

The traditional algorithm was the favored strategy of the pre-service teachers as it was used by $63.5 \%$. Three quarters of the subjects using this strategy presented an appropriate mathematical model. The remaining ones often exchanged dividend and divisor; as exemplified in Figure 7, subject 78 (woman, aged 24) recognized a "sharing situation" because the term "sharing" was included in the wording of the problem. She, however, used the highest figure as the dividend and the lowest as the divisor. About a quarter of the teachers applying the traditional algorithm made the same error. Only $39.4 \%$ of the subjects who used the algorithm achieved the correct solution to this problem.

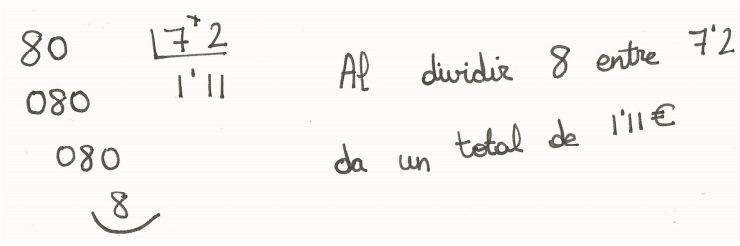

When dividing 8 by 7.2 , the result is $€ 1.11$

Figure 7. Applying the traditional algorithm on an incorrect mathematical model (subject 78, woman, aged 24).

Fifteen per cent of the future teachers who attempted to employ the traditional algorithm provided a correct model $(7.2 \div 8)$ and left the operation in blank. They admitted to have forgotten how to solve divisions with decimals because of the frequent use of calculators at school. Subject 49 (man, aged 22) stated: "I don't know how to solve this division without a calculator." Others confessed to having forgotten the multiplication tables. During her cognitive interview, subject 30 (woman, aged 24) specified: “without a calculator I can't even tell multiplication tables. I just completely forgot the 
multiplication tables of some numbers." Of the subjects who tried to compute the algorithm, $27.3 \%$ did not attain the correct solution. The most common error was in the execution of arithmetic operations, including subtraction and multiplication, as shown by subject 27 and 46 in Figure $8 \mathrm{a}$,b respectively. Subject 27 (woman, aged 21) obtained 6 after subtracting $10^{-2}$. The cognitive interview showed this was a random error due to the fact that subjects do not usually need to work out elementary operations. In fact, subject 27 admitted feeling very embarrassed during the test because of her low level in calculus. Similarly, subject 46 (man, aged 41 ) wrote $8 \times 7=72$. He recognized to have forgotten the multiplication tables: “Really, I don't remember the multiplication tables very well because I don't use them anymore. I wasn't sure whether $8 \times 7$ is equal to 72 or $63 . "$

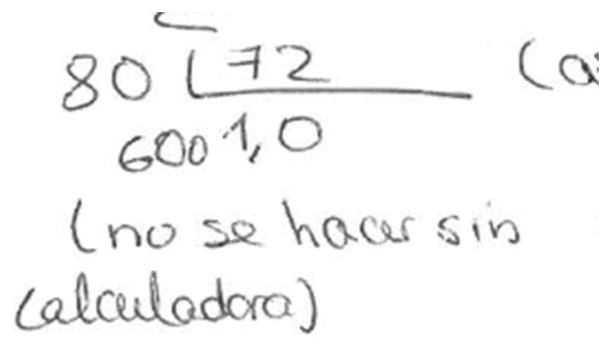

I don't know how to perform it without a calculator

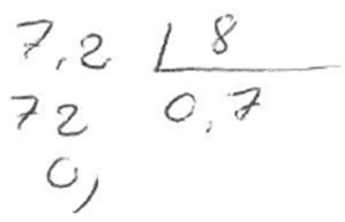

(b)

Figure 8. (a) Subtraction error (subject 27, woman, aged 21) and (b) multiplication error (subject 46, man, aged 41).

About a quarter $(26.3 \%)$ of the subjects computed the traditional algorithm correctly, but did not interpret the solution adequately. They incorrectly reported the currency units, indicating that each friend will receive 0.9 c rather than $€$ 0.9, as shown in Figure 9 (subject 19, woman, aged 25). This suggested that subjects establish a connection between decimal numbers, with zero in the integer part, and cents. In this case, they considered that 0.9 could be expressed in cents rather than euros. The cognitive interviews showed that subjects established a contextual relation between the verbal and written representations of the European currency units. In Spain, we normally refer to "ninety cents" rather than to "zero point nine euros" when verbalizing 0.90 . Therefore, when using currency amounts lower than one, we frequently verbalize "cents" rather than "euros"; for example, 90 c. Similarly, we speak of euros when the entire part is distinct from zero; for example, $€ 1.90$.

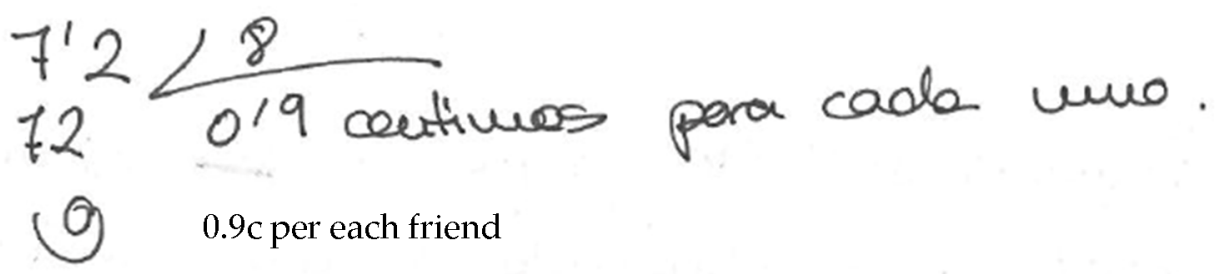

Figure 9. Incorrect units of the quotient (subject 19, woman, aged 25).

\subsubsection{Varying}

The "varying" strategy was applied by $7.7 \%$ of subjects, with $75.0 \%$ of them reaching the correct solution. They all computed the operation mentally. As the cognitive interviews revealed, these future teachers multiplied the dividend by 10 to compute $72 \div 8$, and divided that interim result by 10 to obtain the solution. 


\subsubsection{Guess and Check}

A correct guess and check strategy was applied by $5.7 \%$ of the subjects, using either additive or multiplicative reasoning. An additive reasoning was selected by subjects who were not feeling confident when using the traditional algorithm. Subject 24 (woman, aged 19) expressed: "In this problem, I didn't know how to work out the division [using the traditional algorithm], so I made shares of money, adjusting the leftover amount." These subjects predicted a certain amount of money and added it eight times. Figure 10a shows that the solution was reached after trying with different shares. Subject 81 (woman, aged 25) organized the data in columns and required six attempts to obtain the solution. She began with a random quantity $5 c$, then she continued with $10,25,50 c$, and $€ 1$. After checking with $€ 1$, she observed that she was exceeding the amount of money to be distributed. Thus, she proceeded with a close but lower quantity $(90 \mathrm{c})$ and reached the correct solution.

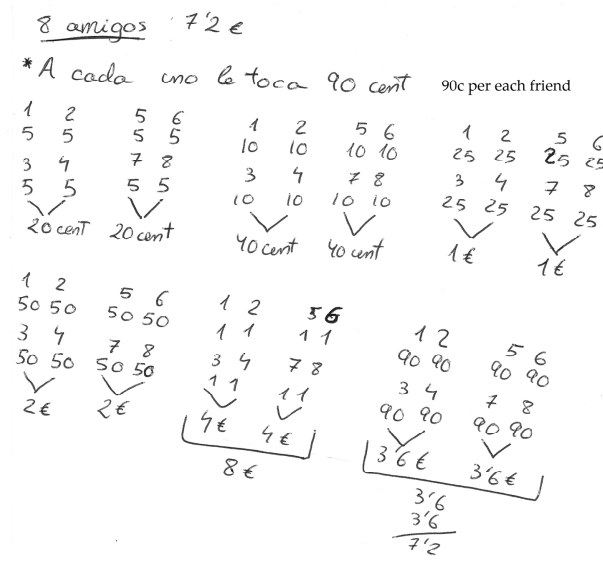

(a)

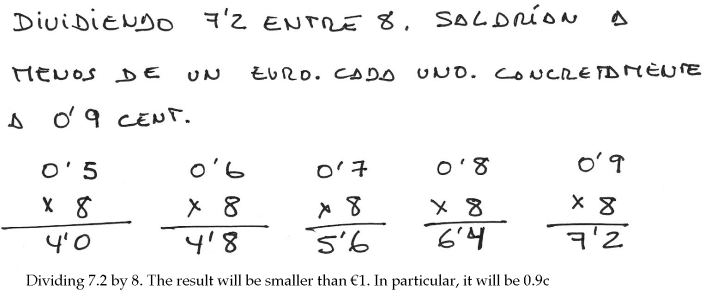

(b)

Figure 10. (a) Guess and check strategy based on additive reasoning (subject 81, woman, aged 25) and (b) guess and check strategy based on multiplicative reasoning (subject 97, man, aged 41).

The subjects who select a multiplicative reasoning searched for the number that when multiplied by 8 is 7.2. As exemplified in Figure 10b, they used the digit-based algorithm of the multiplication. Subject 97 (man, aged 41) knew that he should apply a division to obtain the solution (as he wrote in his response, Figure 10b) but he did not know how to work it out, as explained during the interview. He estimated that the solution would be lower than $€ 1$, and computed a number of multiplications to get the correct one. Like other subjects, he was not feeling confident in carrying out multi-digit divisions.

\subsubsection{Algebraic}

The pre-service teachers who employed an algebraic strategy (3.8\%) chose the proportion formula. This strategy led all subjects to incorrect mathematical models and consequently to incorrect solutions.

\subsection{Chewing Gum Problem}

More than ninety per cent of the subjects attempt to solve the problem: $84.0 \%$ provided an appropriate mathematical model and 59.6\% reached the correct solution. As Table 4 shows, four strategies were identified: "traditional algorithm" (Section 6.3.1), "varying" (Section 6.3.2), "sequential" (Section 6.3.3), and "algebraic" (Section 6.3.4). 
Table 4. Percentage of employed strategies and correct solutions, approaches, and processes on the Chewing gum problem.

\begin{tabular}{ccccc}
\hline Strategy Name & Strategy Employed & Correct Solution & Correct Approach & Correct Process \\
\hline Traditional algorithm & $19.2 \%$ & $60.0 \%$ & $100 \%$ & $60.0 \%$ \\
Varying & $10.6 \%$ & $100 \%$ & $100 \%$ & $100 \%$ \\
Sequential & $25.0 \%$ & $88.5 \%$ & $100 \%$ & $88.5 \%$ \\
Algebraic & $37.5 \%$ & $41.0 \%$ & $69.2 \%$ & $69.2 \%$ \\
\hline
\end{tabular}

\subsubsection{Traditional Algorithm}

The traditional algorithm was selected by $18.5 \%$ of the sample, a ratio lower than in the previous problems. All subjects established an adequate mathematical model $(4.5 \div 0.9)$, but $40.0 \%$ did not correctly execute this operation. Two errors were identified: one concerning the use of decimal numbers, the other related to the use of multiples of ten. Some subjects computed the division by simplifying the commas of the dividend and divisor, and adding a comma to the quotient. This error is exemplified in Figure 11a. Subject 29 (woman, aged 29) wrote: "I removed the comma multiplying by 10. So, I put the comma in the quotient." Other subjects converted euros into cents to avoid the decimal numbers, but still they did not obtain a correct solution. Subject 9 (woman, aged 19), for example, erroneously placed an extra zero in the quotient when executing a division with multiples of ten.

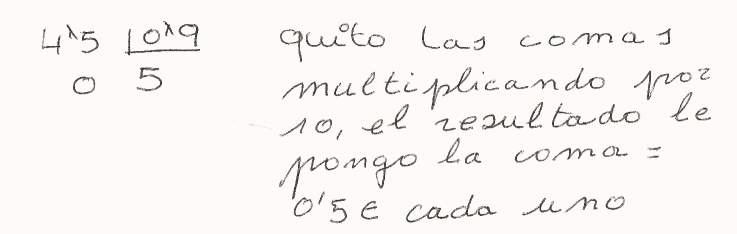

I removed the comma multiplying by 10 . So, I put the comma in the quotient $=€ 0.5$ per one.

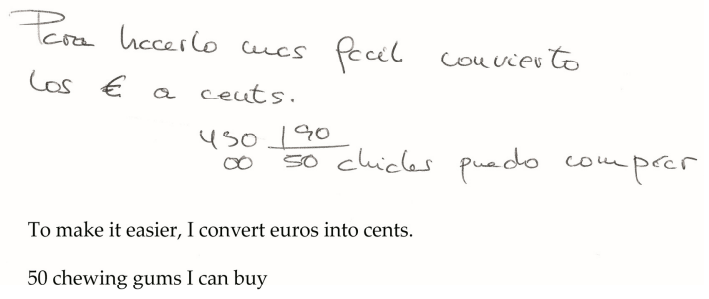

(b)

Figure 11. (a) Error when dividing decimal numbers (subject 29, woman, aged 29); (b) Error when dividing multiples of ten (subject 9, woman, aged 19).

\subsubsection{Varying}

All subjects who employed a varying strategy attained the correct solution through a mental calculation. They multiplied both dividend and divisor by 10 to solve the operation $45 \div 9$. This operation only required knowing multiplication facts.

\subsubsection{Sequential}

One quarter of subjects utilized a sequential strategy based on repeated addition, with nearly $90 \%$ of correct solutions. This strategy was employed by those pre-service teachers who did not remember to compute the traditional algorithm with decimal numbers. Subject 14 (woman, aged 24) stated: "I should make a division removing decimals, but I don't remember how exactly to do it (... ) I know however that I can reach the solution by adding up quantities of 0.9 until obtaining 4.5." Several subjects applied this strategy despite asserting they never learned it from their teachers. Subject 58 (woman, aged 19) wrote: "I didn't learn it at school, but with my parents when shopping." The remaining $10 \%$ of subjects made arithmetic errors. As exemplified in Figure 12, subject 58 did not compute the additions correctly, expressing that $1.8+0.9=2.6$. 


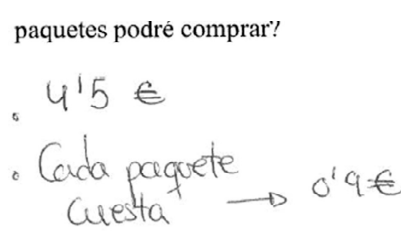

Each package costs $€ 0.9$

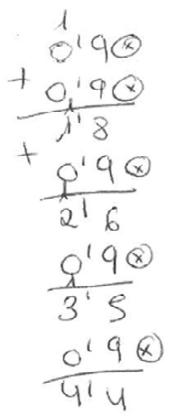

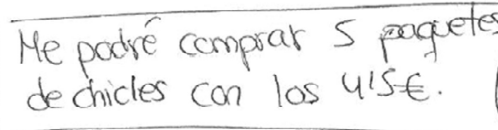

* Esto no lo aprendí en la escuela, sino can mis padies en casa cuecndo haceímos Pa compra.

I could buy 5 chewing gum packages with $€ 4.5$

I didn't learn it at school, but with my parents when shopping

Figure 12. Addition errors (subject 58, woman, aged 19).

\subsubsection{Algebraic}

Algebraic strategies were used by $37.5 \%$ of the sample: $29.8 \%$ attempted to employ the proportion formula, and $7.7 \%$ formulated a linear equation. The proportion formula was a recurring strategy in this problem; all subjects recognized feeling confident with this method as they systematically applied it at school to approach different problems. Sixty per cent of them, however, could not use this strategy to provide an adequate model to approach the problem. Figure 13a,b shows some of the difficulties the subjects faced when establishing the relation between magnitudes. Both subject 6 (woman, aged 23) and subject 73 (woman, aged 20) encountered difficulties associating $€ 0.9$ with the unit of chewing gum, as shown in Figure 13a,b respectively. Subject 73 had also problems finding the equality of ratios; this shows she does not grasp the proportion concept.

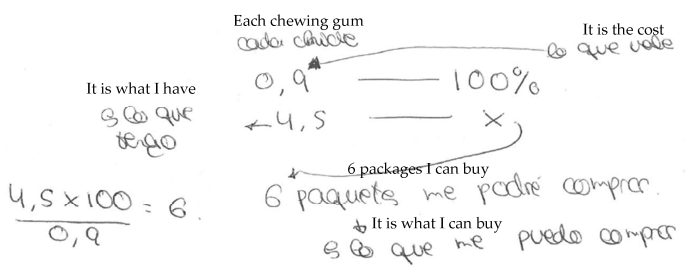

(a)

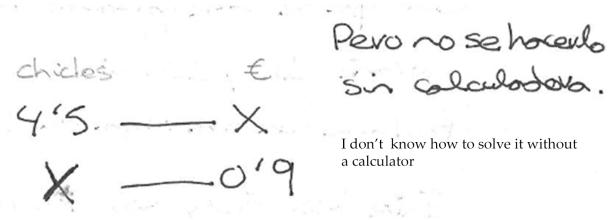

(b)

Figure 13. (a) Erroneous mathematical model (subject 6, woman, aged 23) and (b) erroneous mathematical model (subject 73, woman, aged 20).

Some subjects provided the correct expression to find the unknown value; however, they did not know how to operate divisions. As shown in Figure 14, subject 56 (woman, aged 20) applied correctly the proportion formula, but she still could not work out the division. She explained: "I think it has to be like this, but I can't perform the operation because I don't remember exactly how it should be executed. There may be another way to do it, but I don't remember how." 


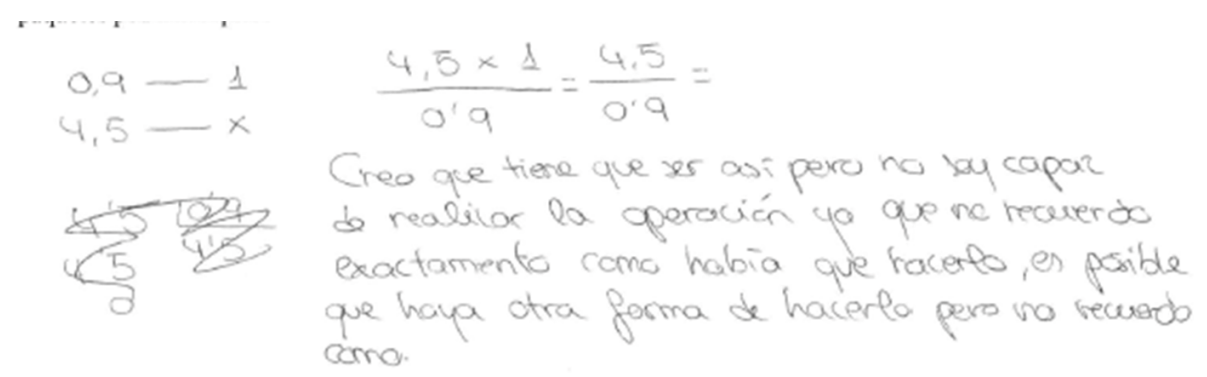

I think it has to be like this, but i can't perform the operation because I don't know remember exactly how it should be executed. There may be another way to do it, but I don't remember how.

Figure 14. Correct application of the proportion formula, and leaving the division in blank (subject 56, woman, aged 20).

About $8 \%$ of the subjects came up directly with a linear equation. All subjects established a correct equation, but as in the example above, several of them did not operate the division. Figure 15 illustrates this process.

$$
\begin{aligned}
& \text { podré comprar? } \\
& X \cdot 0,9=4,5 \\
& X=\frac{4,5}{0,9}
\end{aligned}
$$

$$
\begin{aligned}
& x \text { en los chicer que puedo compoar } \\
& \text { qee eo mültiplico par el dinerco } \\
& \text { que cuerta, axi ea gualo par lo } \\
& \text { que me predo grasrar }
\end{aligned}
$$

$\mathrm{x}$ is the number of chewing gums that I can buy. I multiply this number by the amount of money they cost to match what I can spend.

Figure 15. Approaching a correct linear equation and leaving the division in blank (subject 102, man, aged 25).

\section{Discussion}

This section presents the main findings of the study in relation to previous results in the literature. The results show that the Spanish pre-service teachers made use of six main strategies for solving multi-digit division problems: traditional algorithm, sequential, guess and check, varying, decomposition, and algebraic strategies.

The traditional algorithm was the most employed strategy to solve the problems where either the dividend or divisor were integers (i.e., the inheritance and meal problems). On the chewing gum problem, where both the dividend and divisor were decimal numbers, the traditional algorithm was applied in a smaller proportion. This confirmed the idea that strategy selection depends not only on the problem type, but also on the characteristics of the numbers involved [3,12]. The high usage of the traditional algorithm with integer numbers concurs with the findings of [14] and [16] with primary school students and future primary teachers, suggesting that in Spain the division algorithm is reinforced as school grade increases. This outcome also matched those of $[36,47]$ in the American and Turkish primary school contexts, and differs from those in the Netherlands with students educated under Realistic Mathematics Education, where the algorithm is introduced in the last stage of primary education. As reported by [3], Dutch school students tend to primarily select the column-based strategy rather than the traditional algorithm. The column-based strategy was not identified in this study; this is something expected as this strategy is rarely taught in Spain. It is also noteworthy that the analyses of the present study revealed a high percentage of errors when the future teachers applied the traditional algorithm. These errors related to the omission of zero from the quotient, and also to 
miscalculations when subtracting and multiplying. These outcomes coincide with the ones reported by $[12,13,42,47]$ with primary school students in England, Turkey, Germany, and the Netherlands. Unlike other investigations (e.g., [14]), the pre-service teachers participating in our study did not report the inverse algorithm error. The cognitive interviews did not account further information about this matter.

The sequential and guess and check strategies were normally used as an alternative to the traditional algorithm. Although several teachers gave a blank response because they did not remember the traditional algorithm, others selected one of the aforementioned strategies as a substitute for the algorithm and applied it correctly. Especially, the sequential and guess and check strategies turned out to be generally more effective than the algorithm on Problems 2 and 3, which involved decimal numbers. That is, the percentage of correct applications of these strategies was higher than the traditional method. Similar results were obtained by [36] when assessing the correctness of the sequential strategies employed by U.S. primary school students. Importantly, the cognitive interviews confirmed that the sequential and guess and check strategies were never used as a shortcut to the algorithm, but rather as a marginal solution.

The decomposition and varying strategies were exclusively applied when the pre-service teachers operated mentally. The decomposition strategy was typically executed on division problems with integers, while the varying strategy was employed in the problems with decimals. The relation between varying strategies and mental solutions was previously identified by [8] in a study with Dutch primary school students when solving problems with integers. It is noteworthy that although the majority of the future teachers correctly executed the decomposition strategy, they rarely attempted a contextual interpretation of the solution. These subjects paid more attention to the problem context when using written processes than when applying mental strategies; the studies of $[3,8]$, with Dutch primary school students, generated similar results reporting that written processes often produce more accurate solutions than mental ones.

The use of algebraic strategies was higher in the problems involving decimals: meal and chewing gum. Although the application of algebraic strategies was not a clear choice for approaching these two problems, many of the pre-service teachers attempted to employ them. Previous studies of algebraic and arithmetical strategies have also demonstrated that pre-service teachers tend to apply algebraic strategies in problems where they are often unsuitable [25,26]. In our study, the most recurring algebraic strategy was the proportion formula, identified also by [15] in a recent study with Chilean secondary school students. It appears that, as in the case of the algorithm, the use of the proportion formula is increasing across the educational system. The interviews revealed that the proportion formula was often employed when the subjects did not have a clear idea about how to approach the problems. According to their explanations, they selected this strategy because it is the most common used in secondary education and the one they best recall.

These results show that many of the pre-service teachers participating in this study did not correctly apply the traditional algorithm, in contrast to the objectives of the current Spanish curricula $[1,2]$. They used number-based strategies promoted by both the primary and secondary education curricula (e.g., decomposition, varying and sequential). The decomposition strategy turned out, for instance, to be rather effective for executing the divisions. This was, however, not so successful to reach contextual solutions for the problem requesting an interpretation of the remainder. Regarding the interviews, it seems that the execution of mental strategies increases the lack of contextual interpretations. The subjects were losing track of the problem wording, as they were focused on correctly executing the operation in their head. Additional research, however, would be necessary to further corroborate this finding. The guess and check strategy was rarely used, although its usage always led to a correct solution. Other strategies, promoted mainly in the secondary education curriculum, like the proportion formula, were highly selected for some problems, especially for the one with decimals in both dividend and divisor. The use of this strategy is rather uncommon on division problems and it turned out to be unsuccessful in this study; the subjects who attempted the proportion formula confronted difficulties in 
establishing the mathematical approach. Future longitudinal studies on multi-digit division problems with secondary school students would facilitate the understanding of our results.

\section{Conclusions}

Educational reforms across countries have promoted the application of flexible strategies, in addition to the traditional algorithm, for solving division problems. Many studies have evaluated the division strategies adopted by primary school students [3,5,6,8-13,47]. Investigations on this topic, however, have not been conducted with future early childhood teachers. To bring light into this field of research, the present study analyzed the strategies employed by Spanish future teachers in division problems, the difficulties faced when executing them, and the extent to what strategies were efficiently selected concerning curricular suggestions.

Our results conclude that the Spanish pre-service teachers used a variety of strategies for solving the three proposed multi-digit division problems. At a first glance, this could be interpreted as a rather optimistic outcome because official curricula promote flexible reasoning, handling different problem-solving strategies, and the selection of the most adaptive one in each situation. However, a deeper interpretation of these results shows that subjects did not apply the strategies in relation to its efficiency, but instead to their confidence in solving each problem [51,52]. In the first two problems, involving mainly integers, the subjects essentially applied the traditional algorithm, whereas according to the Spanish curriculum decomposition and varying could be employed as adaptive strategies for the first one and second one, respectively. In the third problem, which required a division with decimals in both divisor and dividend, the strategy most employed was the proportion formula despite the fact that the varying approach may be the most efficient. These observations show that most of the pre-service teachers participating in the study did not choose what $[3,40,41]$ call adaptive strategies.

The traditional algorithm was by large the strategy most applied in the first two problems; however, the majority of the subjects did not execute it correctly. They recognized to have forgotten the steps for its computation due to the massive use of calculators in school. This is a clear symptom that the educational system is sick. If our pre-service early childhood teachers access university without being able to solve multi-digit division problems, it is a significant problem. They would graduate as future teachers without that knowledge and skills because the only mathematics course in their degree does not have a content-knowledge orientation. As a consequence, teachers and educators should rethink the massive use of calculators at school. Otherwise, universities should strongly consider the possibility of undertaking mathematics admission tests for selecting their students. Some Spanish universities are already choosing students through mathematics assessments and/or offering preparatory mathematics courses. In the present study, we also detected that when selecting algebraic strategies, the pre-service teachers failed to provide a correct problem approach, and thus a correct solution. Again, this points out the necessity of revising the instruction at school level and rethinking the entrance requirements for the university teacher-training degrees to avoid feeding back into the system individuals with a lack of mathematics knowledge and skills.

As far as we know, this is the first study evaluating the strategy choice of pre-service early childhood teachers when solving multi-digit division problems, and further research is necessary to corroborate our results. The study also presents some methodological limitations; it was carried out in a single context with a relatively small sample, and consequently outcomes should not be generalized into other contexts. Cross-cultural studies would be required to better identify and compare the contextual factors affecting teachers' strategy choice in division problems. A larger sample would also help investigate further into the particularities of number-based strategies, and to establish more consistent relationships between strategy choice and errors made. At the same time, it would be relevant to determine the relationship between pre-service teachers' self-confidence in mathematics and strategy choice for solving division problems. Empirical investigations with secondary school students would also be appropriate to identify the extent to which the pre-service teachers' selection and execution of division strategies is affected by lower, middle, or upper school instruction. 
Author Contributions: Conceptualization, Z.O.-L.; methodology, Z.O.-L.; software, Z.O.-L.; formal analysis, Z.O.-L.; investigation, Z.O.-L.; resources, Z.O.-L. and J.-M.D.-M.; data curation, Z.O.-L.; writing-original draft preparation, Z.O.-L.; writing-review and editing, J.-M.D.-M.; visualization, J.-M.D.-M.; supervision, J.-M.D.-M.; project administration, J.-M.D.-M.; funding acquisition, J.-M.D.-M. Both authors have read and agreed to the published version of the manuscript.

Funding: This research was funded by Erasmus+ programme, grant numbers 2019-1-CZ01-KA201-061377 and 2020-1-ES01-KA201-082102; and FEDER/Ministerio de Ciencia, Innovación y Universidades-Agencia Estatal de Investigación/, grant number EDU2017-84979-R.

Acknowledgments: During the elaboration of this manuscript, Zaira Ortiz-Laso was a pre-doctoral student at the Universidad de Cantabria under the supervision of José-Manuel Diego-Mantecón. We thank Teresa F. Blanco of the Universidad de Santiago de Compostela for her suggestions in this article.

Conflicts of Interest: The authors declare no conflict of interest.

\section{References}

1. Real Decreto 126/2014, de 28 de Febrero, por el que se Establece el Currículo Básico de la Educación Primaria, 2014. Available online: https://www.boe.es/buscar/pdf/2014/BOE-A-2014-2222-consolidado.pdf (accessed on 9 October 2020).

2. Real Decreto 1105/2014, de 26 de Diciembre, por el que se Establece el Currículo Básico de la Educación Secundaria Obligatoria y del Bachillerato, 2014. Available online: https://www.boe.es/boe/dias/2015/01/03/ pdfs/BOE-A-2015-37.pdf (accessed on 9 October 2020).

3. Hickendorff, M.; Van Putten, C.M.; Verhelst, N.D.; Heiser, W.J. Individual differences in strategy use on division problems: Mental versus written computation. J. Educ. Psychol. 2010, 102, 438-452. [CrossRef]

4. Camos, V.; Baumer, J. Why is it so hard to solve long divisions for 10-year-old children? Int. J. Sch Cog Psychol. 2015, 2, 007. [CrossRef]

5. Hickendorff, M. Dutch sixth graders' use of shortcut strategies in solving multidigit arithmetic problems. Eur. J. Psychol. Educ. 2018, 33, 577-594. [CrossRef]

6. Hickendorff, M.; Torbeyns, J.; Verschaffel, L. Grade-related differences in strategy use in multidigit division in two instructional settings. Br. J. Dev. Psychol. 2017, 36, 169-187. [CrossRef]

7. Robinson, K.M.; Arbuthnott, K.D.; Rose, D.; McCarron, M.C.; Globa, C.A.; Phonexay, S.D. Stability and change in children's division strategies. J. Exp. Child. Psychol. 2006, 93, 224-238. [CrossRef] [PubMed]

8. Auer, M.F.F.; Hickendorff, M.; Van Putten, C.M. Solution strategies and adaptivity in multidigit division in a choice/no-choice experiment: Student and instructional factors. Learn. Instr. 2016, 41, 52-59. [CrossRef]

9. Auer, M.F.F.; Hickendorff, M.; Van Putten, C.M. Training can increase students' choices for written solution strategies and performance in solving multi-digit division problems. Front. Psychol. 2018, 9, 1644. [CrossRef]

10. Auer, M.F.F.; Hickendorff, M.; Van Putten, C.M.; Béguin, A.A.; Heiser, W.J. Multilevel latent class analysis for large-scale educational assessment data: Exploring the relation between the curriculum and students' mathematical strategies. Appl. Meas. Educ. 2016, 29, 144-159. [CrossRef]

11. Schulz, A. Relational reasoning about numbers and operations-Foundation for calculation strategy use in multi-digit multiplication and division. Math. Think. Learn. 2018, 20, 108-141. [CrossRef]

12. Schulz, A.; Leuders, L. Learning trajectories towards strategy proficiency in multi-digit division-A latent transition analysis of strategy and error profiles. Learn. Individ. Differ. 2018, 66, 54-69. [CrossRef]

13. Anghileri, J.; Beishuizen, M.; Van Putten, K. From informal strategies to structured procedures: Mind the gap! Educ. Stud. Math. 2002, 49, 149-170. [CrossRef]

14. Ivars, P.; Fernández, C. Problemas de estructura multiplicativa: Evolución de niveles de éxito y estrategias en estudiantes de 6 a 12 años. Educación Matemática 2016, 28, 9-38. [CrossRef]

15. Márquez, M.; Arredondo, E.H.; García-García, J.I. Estrategias en la resolución de problemas de división-medida por estudiantes de séptimo básico en Chile. Espacios 2019, 40, 10.

16. Fernández, C.; Callejo de la Vega, M.L.; Márquez Torrez, M. Conocimiento de los estudiantes para maestro cuando interpretan respuestas de estudiantes de primaria a problemas de división-medida. Enseñanza de las Ciencias 2014, 32, 407-424. [CrossRef]

17. Kaasila, R.; Pehkonen, E.; Hellinen, A. Finnish pre-service teachers' and upper secondary students' understanding of division and reasoning strategies used. Educ. Stud. Math. 2010, 73, 247-261. [CrossRef] 
18. Pehkonen, E.; Kaasila, R. Misleading strategies used in a non-standard division problem. In problem solving in mathematics education. In Proceedings of the 11th ProMath Conference, Budapest, Hungary, 3-6 September 2009; pp. 103-113.

19. Muñoz-Catalán, M.C.; Liñán-García, M.M.; Ribeiro, M. Conocimiento Especializado para Enseñar la Operación de Resta en Educación Infantil. Cadernos de Pesquisa 2017, 24, 4-19. [CrossRef]

20. Ball, D.L.; Thames, M.H.; Phelps, G. Content Knowledge for Teaching: What Makes It Special? J. Teac. Educ. 2008, 59, 389-407. [CrossRef]

21. Carrillo, J.; Climent, N.; Montes, M.; Contreras, L.C.; Flores-Medrano, E.; Escudero-Ávila, D.; Vasco, D.; Rojas, N.; Flores, P.; Aguilar-González, A.; et al. The mathematics teacher's specialised knowledge (MTSK) model. Res. Math. Educ. 2018, 20, 236-253. [CrossRef]

22. Shulman, L.S. Those who understand: Knowledge growth in teaching. Educ. Res. 1986, 15, 4-14. [CrossRef]

23. Schoenfeld, A.H.; Kilpatrick, J. Toward a theory of proficiency in teaching mathematics. In International Handbook of Mathematics Teacher Education; Tirosh, D., Wood, T., Eds.; Sense Publishers: Rotterdam, The Netherlands, 2008; Volume 2, pp. 321-354. [CrossRef]

24. Mulligan, J. Children's solutions to partition problems. In Proceedings of the 15th Mathematics Education Conference Research Group of Australasia, Sydney, Australia, 4-8 July 1992; pp. 410-412.

25. Van Dooren, W.; Verschaffel, L.; Onghena, P. Pre-service teachers' preferred strategies for solving arithmetic and algebra word problems. J. Math. Teacher Educ. 2003, 6, 27-52. [CrossRef]

26. Van Dooren, W.; Verschaffel, L.; Onghena, P. The impact of preservice teachers content knowledge on their evaluation of students' strategies for solving arithmetic and algebra word problems. J. Res. Math. Educ. 2002, 33, 319-351. [CrossRef]

27. Downton, A. It Seems to matters not whether it is partitive or quotitive division when solving one step division problems. In Proceedings of the 32nd annual conference of the Mathematics Education Research Group of Australasia, Palmerston North, New Zealand, 5-9 July 2009; pp. 161-168.

28. Simon, M.A. Prospective elementary teachers' knowledge of division. J. Res. Math. Educ. 1993, 24, $233-254$. [CrossRef]

29. Squire, S.; Bryant, P. Children's models of division. Cogn. Dev. 2003, 18, 355-376. [CrossRef]

30. Neuman, D. Early learning and awareness of division: A phenomenographic approach. Educ. Stud. Math. 1999, 40, 101-128. [CrossRef]

31. Fischbein, E.; Deri, M.; Nello, M.S.; Marino, M.S. The role of implicit models in solving verbal problems in multiplication and division. J. Res. Math. Educ. 1985, 16, 3-17. [CrossRef]

32. Graeber, A.O.; Tirosh, D.; Glover, R. Teachers' misconceptions in solving verbal problems in multiplication and division. J. Res. Math. Educ. 1989, 20,95-102. [CrossRef]

33. Cai, J.; Silver, E.A. Processes and interpretations of solutions in solving a division-with-remainder story problem: Do Chinese and US students have similar difficulties? J. Res. Math. Educ. 1995, 26, 491-497. [CrossRef]

34. Chen, L.; Van Dooren, W.; Chen, Q.; Verschaffel, L. An investigation on Chinese teachers' realistic problem posing and problem solving ability and beliefs. Int. J. Sci. Math. Educ. 2011, 9, 919-948. [CrossRef]

35. Contreras, L.C.; Carrillo, J.; Zakaryan, D.; Muñoz-Catalán, M.C.; Climent, N. Un estudio exploratorio sobre las competencias numéricas de los estudiantes para maestro. Bolema Math. Educ. Bull. 2012, 26, $433-457$. [CrossRef]

36. Silver, E.A.; Shapiro, L.J.; Deutsch, A. Sense making and the solution of division problems involving remainders: An examination of middle school students' solution processes and their interpretations of solutions. J. Res. Math. Educ. 1993, 24, 117-135. [CrossRef]

37. Rodríguez, P.; Lago, M.O.; Hernández, M.L.; Jiménez, L.; Guerrero, S.; Caballero, S. How do secondary students approach different types of division with remainder situations? Some evidence from Spain. Eur. J. Psychol. Educ. 2009, 24, 529-543. [CrossRef]

38. Cooper, B.; Harries, T. Making sense of realistic word problems: Portraying working class 'failure' on a division with remainder problem. Int. J. Res. Method Educ. 2005, 28, 147-169. [CrossRef]

39. Lemaire, P.; Siegler, R.S. Four aspects of strategic change: Contributions to children's learning of multiplication. J. Exp. Psychol. Gen. 1995, 124, 83-97. [CrossRef] [PubMed] 
40. Siegler, R.S.; Shipley, C. Variation, selection and cognitive change. In Developing Cognitive Competence: New Approaches to Process Modeling; Simon, T.J., Halford, G.S., Eds.; Erlbaum: Hillsdale, MI, USA, 1995; pp. 31-76. [CrossRef]

41. Hickendorff, M.; Torbeyns, J.; Verschaffel, L. Multi-digit addition, subtraction, multiplication, and division strategies. In International Handbook of Mathematical Learning Difficulties: From the Laboratory to the Classroom; Fritz, A., Haase, V.G., Räsänen, P., Eds.; Springer: Cham, Switzerland, 2019; pp. 543-560. [CrossRef]

42. Van Putten, C.M.; Van den Brom-Snijders, P.A.; Beishuizen, M. Progressive mathematization of long division strategies in Dutch primary schools. J. Res. Math. Educ. 2005, 36, 44-73.

43. Murray, H.; Olivier, A.; Human, P. Fifth graders' multi-digit multiplication and division strategies after five years' problem-centered learning. In Proceedings of the International Conference for the Psychology of Mathematics Education, Lisbon, Portugal, 29 July-3 August 1994; pp. 399-406.

44. Öçal, M.F.; Şen, C.; Güler, G.; Kar, T. The investigation of prospective mathematics teachers' non-algebraic solution strategies for word problems. Int. J. Math. Educ. Sci. Technol. 2020, 51, 563-584. [CrossRef]

45. Mulligan, J. Children's solutions to multiplication and division word problems: A longitudinal study. Math. Ed. Res. J. 1992, 4, 24-41. [CrossRef]

46. Ramírez-Esperón, M.M.E.; Páez, D.A.; Eudave-Muñoz, D.; Martínez-Rizo, F. El aprendizaje autónomo, favorecedor de la experiencia adaptativa en alumnos y docentes: La división con números decimales. Educación Matemática 2019, 31, 38-65. [CrossRef]

47. İncikabı, L.; Ayanoğlu, P.; Uysal, R. Sixth-Grade students' procedural and conceptual understandings of division operation in a real-life context. Int. Electron. J. Elem. Educ. 2020, 13, 35-45. [CrossRef]

48. Field, A. Discovering Statistics Using SPSS, 3rd ed.; Sage Publications: London, UK, 2009.

49. Caicedo-Cavagnis, E.; Zalazar-Jaime, M.F. Entrevistas cognitivas: Revisión, directrices de uso y aplicación en investigaciones psicológicas. Revista Avaliação Psicológica 2018, 17, 362-370. [CrossRef]

50. Osborn, M. New methodologies for comparative research? Establishing 'constants' and 'contexts' in educational experience. Oxf. Rev. Educ. 2004, 30, 265-285. [CrossRef]

51. Diego-Mantecón, J.M.; Córdoba-Gómez, F.J. Adaptación y validación del MRBQ (mathematics related beliefs questionnaire) al contexto colombiano con estudiantes de secundaria. Educación Matemática 2019, 31, 66-91. [CrossRef]

52. Diego-Mantecón, J.M.; Blanco, T.F.; Chamoso, J.M.; Cáceres, M.J. An attempt to identify the issues underlying the lack of consistent conceptualisations in the field of student mathematics-related beliefs. PLoS ONE 2019, 14, 0224696. [CrossRef] [PubMed]

Publisher's Note: MDPI stays neutral with regard to jurisdictional claims in published maps and institutional affiliations.

(C) 2020 by the authors. Licensee MDPI, Basel, Switzerland. This article is an open access article distributed under the terms and conditions of the Creative Commons Attribution (CC BY) license (http://creativecommons.org/licenses/by/4.0/). 